\title{
Word-retrieval in two cases of progressive supranuclear palsy
}

\author{
Jennifer M. Gurd' ${ }^{1}$ and John R. Hodges ${ }^{2}$
}

'University Department of Clinical Neurology, The Radcliffe Infirmary, Oxford, and
'University Neurology Unit, Addenbrooke's Hospital and MRC Applied Psychology
Unit, Cambridge, UK

Correspondence to: Jennifer M. Gurd, Neuropsychology Unit, University

Department of Clinical Neurology, The Radcliffe Infirmary, Woodstock Road, Oxford, OX2 6HE, UK

\begin{abstract}
In this paper, we describe the detailed neuropsychological investigation of two cases of progressive supranuclear palsy (PSP) and demonstrate word-finding difficulties associated with pervasive problems in word-retrieval. The pattern of deficits resembles that seen in Parkinson's Disease (PD) but is more severe, even in very mild PSP, and appears less amenable to cue facilitation. Performance on a variety of word-production tasks is compared, and experimental controls for motor effects on performance are included. The role of stimulus cues in speeded word-finding is addressed experimentally, as are central executive influences on task performance. This combines with functional brain-scan data from single photon emission computed tomography (SPECT) which shows reduced frontal perfusion in one of the two cases.
\end{abstract}

Keywords: Progressive supranuclear-palsy, - Anomia - Neuropsychology, psychology - Dementia

\section{INTRODUCTION}

Van der Hurk and Hodges (1995) suggest that, in progressive supranuclear palsy (PSP), semantic memory impairments are caused by retrieval problems resulting from frontal lobe deactivation. It has further been claimed that these word-retrieval problems are due to impaired search mechanisms (Litvan et al., 1989). In this paper, we provide evidence to corroborate such previously unsupported claims.

The aim of our study was to determine the nature, extent, and cause of semantic word-finding difficulties in PSP. There are some similarities between PSP and Parkinson's Disease (PD), in that word-finding deficits are well-documented in PD (Gurd, 1993; Gurd and Marshall, 1995) and, in both groups, there is damage to the basal ganglia and substantia nigra (Agid et al., 1986). The distinction is that the caudate nucleus and the putamen are affected to the same extent in PSP whereas, in PD, the putamen is more severely affected than the caudate (Agid et al., 1989).

Progressive supranuclear palsy, also known as Steele-Richardson-Olszewski syndrome (Steele et al., 1964), is a rare, progressive, non-familial multisystem degenerative disorder with usual onset in middle or old age (Young, 1985; Barr, 1986). The hallmark of PSP is the vertical gaze palsy with a history of prominent postural instability, although a range of clinical features, including axial dystonia and rigidity, pseudobulbar palsy, bradykinesia and rigidity, frontal lobe signs (bradyphrenia, perseveration, forced grasping and utilization behaviour), may occur (Lees, 1987). Recently, clinical research criteria for possible, probable and definite PSP have been proposed (Litvan et al., 1996). Neuropathological abnormalities are typically found in the globus pallidus, subthalamic nucleus, substantia nigra (compacta and reticulata), superior colliculi, pretectal area, peri-aqueductal grey matter and nuclei pontis. Other areas which may be affected include the dentate nucleus, red nucleus, locus ceruleus, corpus striatum, thalamus, olive, nucleus cuneiformis, nucleus subcuneiformis, septum, hippocampus, frontal cortex, nuclei of III, IV, VI, XII cranial nerves, spinal cord and posterior hypothalamus. The amygdala, cerebellar cortex, temporal neocortex, parietal neocortex, and occipital neocortex are rarely affected (Lees, 1987; Daniel et al., 1995). It is still unclear what causes the disease and it remains comparatively intractable to treatment (Agid et al., 1986). Reduced bilateral frontal metabolism has been demonstrated on positron emission 
tomography (PET) (D'Antona et al., 1985) and this has been associated with cognitive impairments in PSP (Pierrot-Deseilligny et al., 1989; Pillon et al., 1995).

To date, there have been comparatively few attempts to apply single-case experimental neuropsychology methods to describe the disorder. One of the most striking and consistent findings in PSP is the reduction in verbal fluency on both phonemic (initial letter) and semantic category tasks (Rosser and Hodges, 1994; Esmonde et al., 1996). This impairment has been linked to the psycholinguistic processes of initiation, search, verification and retrieval from semantic memory and to working memory functions (Frith et al., 1991; Burgess and Shallice, 1994). Our investigations focus on the specific dysfunctions underlying verbal fluency and other word-finding problems in two welldocumented cases of PSP; one with mild and one with more advanced disease. Previous reports have tended to focus on grouped results over a small number of standardized clinical tests. By describing individual cases in greater experimental detail, we seek to clarify the nature of cognitive deficits found at different stages of PSP.

\section{SUBJECTS}

Case 1 was a right-handed housewife born in 1931. She first presented in October 1985 with a nine-month history of difficulty in concentrating, mild depression, and flattening of affect, with early morning awakening and decreased appetite, but no psychotic features. Clumsiness of gait and difficulty co-ordinating fine hand movements had been noted by the patient. There had been occasional transient diplopia and difficulty focusing on fine visual stimuli at close distance. On one occasion, she had inexplicably fallen downstairs. Her inappropriate affective responses had been troubling to her as, for example, she developed uncontrollable giggling, even in her Bible class. (She was subsequently tested by JG, in 6/87, 10/87 and 01/88).

There was no past medical history. She had never smoked and rarely drank alcohol. There was no family history of neurological disease and general medical examination was unremarkable. Her head posture was normal. Spontaneous gait was unremarkable but heelto-toe walking was performed poorly. Eye movements were definitely abnormal; horizontal and vertical saccadic movements were slow and disrupted. Horizontal pursuit was full but vertical pursuit movements were limited to approximately 30 degrees total range. Vertical opticokinetic response (OKN) was absent and horizontal responses were poor, particularly when the drum rotated to the left. The remainder of the cranial nerves were unremarkable. The tone in her limbs was normal but there was mild nuchal rigidity. Power was full; reflexes were symmetrically brisk, with positive finger jerks and bilateral extensor plantars. Frontal release signs were present with a strongly positive pout response and bilateral palmar-mental reflexes but there was no grasping or glabellar tap. CT scan of the brain was normal. EEG revealed normal background alpha rhythm with superimposed excessive amounts of theta range activity and irregular fast waves which were most marked in the temporal areas. Cerebral perfusion scintigraphy was carried out using $500 \mathrm{Mbq}$ Technetium-99m HMPAO and single-photon-emission computed tomography (SPECT). This showed mild hypoperfusion of the frontal lobes; there was a possible breach in the cortical uptake in the left fronto-parietal area (section 15) and in the right fronto-parietal area (section 22) (see Fig. 1). Other routine investigations were unremarkable, including CSF examination, thyroid function, autoantibodies, haematology and routine biochemistry. A diagnosis of probable PSP was made, in keeping with the research criteria proposed by Litvan et al. (1996), based on the disturbed eye movements, gait abnormality, extrapyramidal, and frontal features. She was treated with a course of

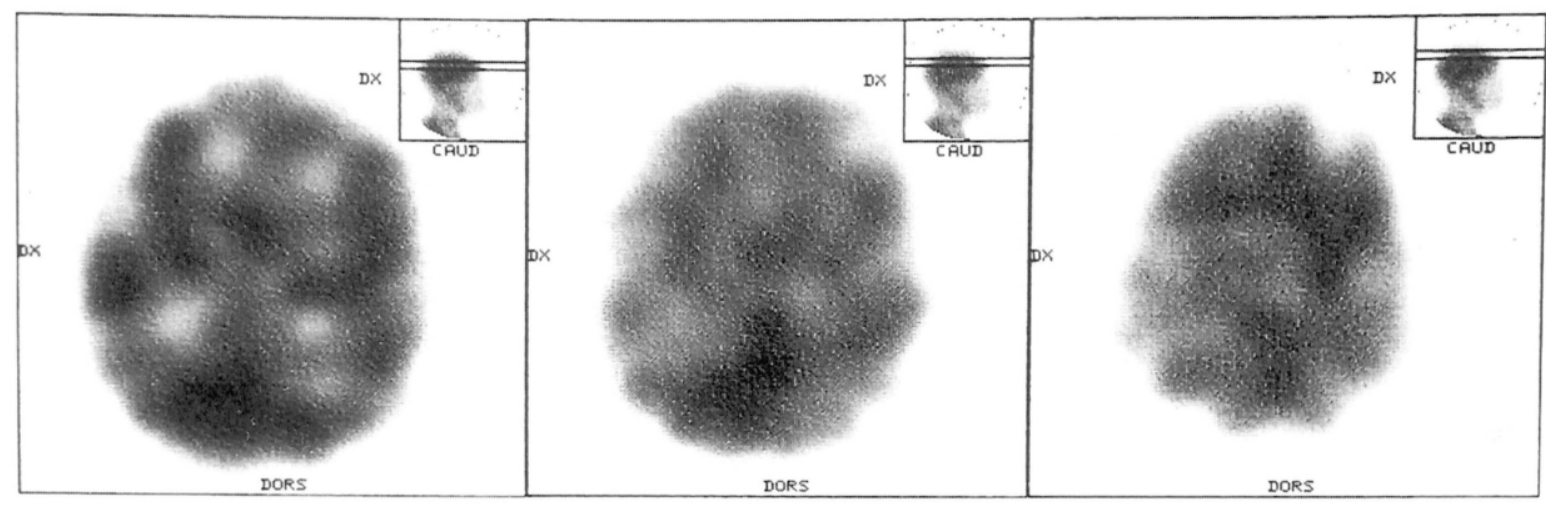

FIG. 1. Case 1, Spect scan showing near normal cerebral perfusion. 


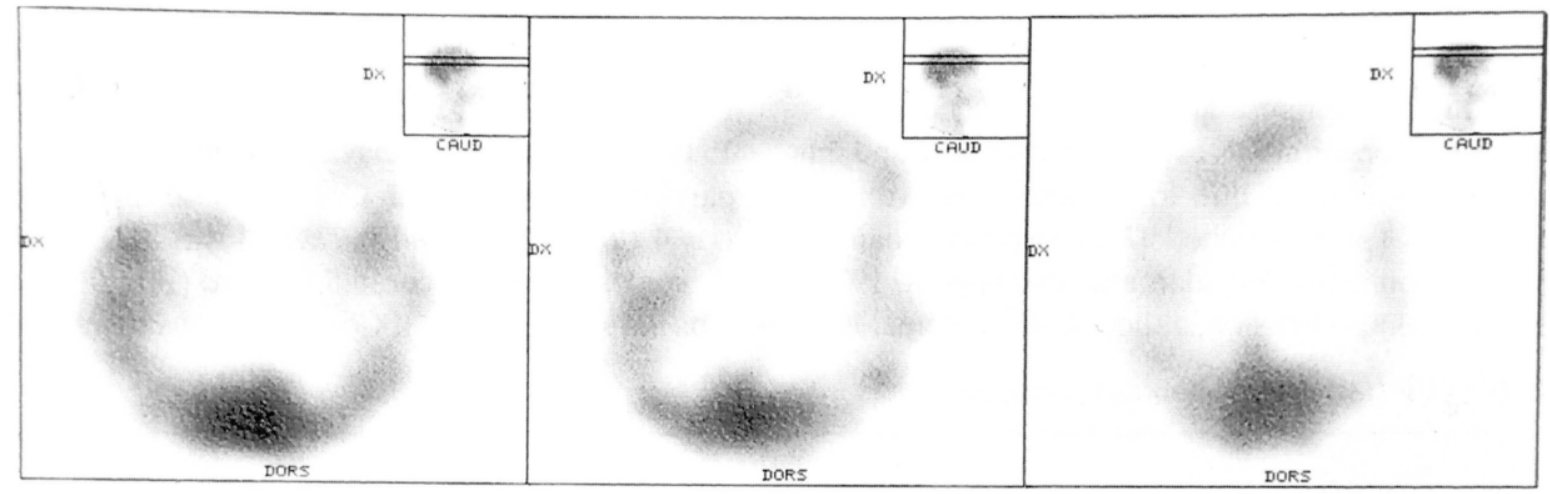

FIG. 2. Case 2, Spect scan, showing frontal hypoperfusion.

tricyclic antidepressants which improved her mood. Over the subsequent six months there was little change in her clinical state.

Case 2 was a right-handed housewife born in 1926. She presented in March 1987 with an eight-month history of frequent falls and postural instability. This was followed by progressive dysphagia and mild dysarthria. (She was subsequently tested in $7 / 88$ and $10 / 88$ by JG.) There was no past medical or family history of note and, on examination, she showed characteristic staring faces with reduced spontaneous blinking and head retraction. Eye movements were abnormal with extremely limited vertical pursuit (approximately five degrees). Horizontal pursuit was full but obviously slow. Vertical saccades were absent and horizontal saccades were disrupted and jerky. Dolls' head manoeuvres with gaze fixation significantly improved her range of vertical movements. Pupillary responses were normal. Despite obvious dysarthria, there were no bulbar signs, such as problems with palatal movement or tongue protrusion. Tone was increased in the nuchal muscles and the head was held in an extended posture. Peripheral muscle tone was mildly increased in all groups and was extrapyramidal in type. There was no limb weakness. Deep tendon reflexes were symmetrically brisk and plantar responses were flexor. There were no sensory abnormalities. The disturbance in gait was marked, with a broad-based tentative gait and particular difficulty in turning and/or changing directions, which is characteristic of PSP. There were marked frontal release signs of pouting, palmar-mentals and glabellar tap.

CT scan of the brain showed a moderate degree of diffuse cerebral atrophy which was more prominent than would be expected for her age. There was widening of the cortical sulci and mild ventricular enlargement, which were both slightly more pronounced on the left. Other routine investigations were unremarkable. The clinical presentation and physical signs were compatible with a diagnosis of probable PSP, as defined by recent research criteria (Litvan et al., 1996). She was started on Madopar (125mg three times per day) but there was no substantial improvement in symptoms so this was discontinued. Over the next six months, her condition deteriorated and her postural instability worsened. She became unable to walk unaided. Her dysphagia had also increased to such a degree that she was experiencing difficulty with swallowing liquids. By February 1988 (20 months postonset), she could walk only with a person supporting her and her speech was extremely slow and effortful. SPECT using $500 \mathrm{Mbq}$ Technetium-99m HMPAO in May 1988 showed markedly decreased frontal perfusion covering all sections (see Fig. 2).

Background Neuropsychology. To enable comparison of the two patients' scores across a number of tasks, the scores are presented as raw values, and as scores converted to Z-values, with reference to control subjects described in Gurd (1993 [Chapter 2: $\mathrm{N}=24$, mean age $=65.50$ years, $\mathrm{SD}=7.07$; and Chapter $5: \mathrm{N}=27$, mean age $=63.11$ years, $\mathrm{SD}=12.48]$ ). From Table I, it can be seen that Case I had a NART (Nelson and O'Connell, 1978) estimated pre-morbid IQ of 119 as compared to Case 2's value of 104. Both women had significantly reduced confrontation picture-naming scores on the Boston Naming Test (Goodglass and Kaplan, 1983); 83\% ( $Z=-2.11)$ and 71\% $(Z=-4.72)$, respectively. Case 2 had lower than predicted WAIS-R (Wechsler, 1981) Vocabulary (SS = 8) and Similarities $(\mathrm{SS}=8)$ scores, given her overall NART-predicted full-scale IQ of 104. The IQ measurements and scores on both Similarities and Vocabulary subsets for Case 2 were in line with her Raven's Progressive Matrices (Raven, 1958) score of 50th centile correct. Written 
picture description data were available for Case 1; her paragraph was somewhat disorganized with one ungrammatical sentence and a loss of function words. Case 2's conversation was extremely dysarthric and difficult to comprehend due to reduced vocal volume. Nonetheless, Case 2 attained $97 \%$ correct on a naming to description test (Coughlan and Warrington, 1978). Language comprehension, although not systematically tested, appeared to be intact.

Memory scores showed intact performance for both PSP patients on the Wechsler paragraph (Wechsler, 1945) immediate and delayed scores. Digit spans were particularly reduced for Case 2 whose digits forward was $4(Z=-2.23)$, and backward was $3(Z=-1.89)$. By contrast, Case 1 scored 5 forward $(Z=-1.43)$, and 4 backward $(Z=1.14)$. Corsi block spans were below

TABLE I. PSP background neuropsychology

Case $1 \quad$ Case 2

1.) $I Q:$

2.) Language:

$\begin{array}{ll}\text { NART-IQ } & \\ \text { WAIS } & \text { Information } \\ \text { (age-scaled) } & \text { Comprehension } \\ & \text { Arithmetic } \\ & \text { Similarities } \\ & \text { Digit span } \\ & \text { Vocabulary } \\ & \text { Digit symbol } \\ & \text { Picture completion } \\ & \text { Block design } \\ & \text { Picture arrangement } \\ & \text { Object assembly } \\ & \text { Verbal IQ } \\ & \text { Performance IQ } \\ & \text { Full scale IQ }\end{array}$

Naming

Boston Naming (\% correct) controls

Coughlan \& Warrington (\% correct) naming to description

3.) Memory:

Digit Span

forward

backwards

Corsi blocks

controls

controls

controls

Wechsler Paragraph Recall

immediate

delay (30 min) controls

Rey Figure

copy

recall (30 $\mathrm{min})$

Benton Visual Retention (correct)

4.) Other:

Raven's Progressive Matrices

Wisconsin Card Sorting

(controls: mean 2.82 (SD 1.47) categories)

Mood (HAD) controls

$$
\text { Anxiety (cut-off }=8 \text { ) }
$$

Depression (cut-off $=8$ )

119
13
14
11
15
9
13
10
10
10
12
14
116
106
113

$83\left(Z=-2.11^{\star}\right)$

92.75 (SD 4.61)

$-$

$\begin{array}{ll}5(Z=-1.43 \mathrm{SD}) & 4\left(Z=-2.23^{\star} \mathrm{SD}\right) \\ 6.79(S D 1.25) & \\ 4(Z=-1.14 \mathrm{SD}) & 3(Z=-1.89 * S D) \\ 5.50(S D 1.32) & \\ 5(Z=-0.47 \mathrm{SD}) & 4(Z=-1.46 \mathrm{SD}) \\ 5.47(S D 1.01) & \\ 13(Z=+0.71 \mathrm{SD}) & 10(Z=0.26 \mathrm{SD}) \\ 10.80(S D 3.10) & \\ 8.50(Z=0.00 \mathrm{SD}) & 9(Z=+0.17 \mathrm{SD}) \\ 8.50(3.00) & \\ 24 / 36(25 \text { th centile }) & - \\ 19.5 / 36(25 \text { th centile }) & - \\ 5(Z=-1.94 \star S D) & 6(Z=-1.57 \mathrm{SD}) \\ 10.17(S D 2.66) & \end{array}$

$-$

50th centile

0 categories

50 errors

8 (first measure) 1

10 (first measure) 11

5 (subsequent measure)

Key: Z = Z-score ([control mean - value]/ control standard deviation)

* = significant impairment $(p<.05)$

34 Behavioural Neurology • Vol 10 • 1997 
average but within normal limits (Case $1=5$, $Z=-0.47$; Case $2=4, Z=-1.46$ ). The Rey Figure (Rey, 1941) was poorly copied and recalled by Case 1 , and Case 2 could not perform the task. Both women performed poorly on the Benton Visual Retention Test (Benton, 1974).

Although Case 1 scored well on all WAIS subtests, she was unable to attain correctly any categories on the Wisconsin Card Sorting Test (short version) (Berg, 1948). Mood scores on the self-rating Hospital Anxiety and Depression scale (HAD; Zigmond and Snaith, 1983) showed that Case 1 scored above the clinical cutoff for both anxiety (8) and depression (10) on one occasion. On subsequent test sessions, her HAD values were within normal limits. Case 2 was not anxious (1) but self-scored as depressed (11). Both patients became easily fatigued and they were difficult to test. We used multiple short testing sessions for both patients, and Ethics committee approval was obtained for the study.

\section{METHODS}

To separate the effects of articulation from those of word-finding impairments, a number of tests were administered.

Automatic speech rate. The speeded recitation of overlearned categories, such as days of the week and months of the year, was measured.

Continuous series. Alternating automatic speech, referred to here as continuous series, was included to tap central executive task-switching functions. The number of categories being alternated was titrated between two and four, per task type (Gurd, 1993; Gurd and Marshall, 1995). Subjects were asked to recite overlearned sequences, such as days of the week, letters of the alphabet, and months of the year, in alternation. For example, the subject may say "Monday, A, Tuesday, B..." or, in a subsequent fourswitch sequence: "Monday, A, 1, January, Tuesday, B, 2, February...etcetera". Performance to criterion was set at (a) completion of all the 21 iterations and (b) at least $80 \%$ of items produced correctly.

Speeded picture naming. This was assessed using 60 pictures from Snodgrass and Vanderwart (1980). These were aligned 20 to a page $(5 \times 4)$ and subjects were asked to name these high frequency pictures rapidly, as if reading words from a page. Thus, cued word-retrieval rates could be compared with rates of uncued word-retrieval in verbal fluency.
Verbal fluency. We used 12 different verbal fluency tasks, each with a duration of two minutes, with four alternating and eight single counterbalanced conditions. In Table II, they are listed in the order in which they were administered.

Articulation. This was measured using the Boston Diagnostic Aphasia Battery (BDAE) scale for articulation and oral agility, as well as a single phoneme repetition measure (Sawashima, 1980). The single syllables $/ \mathrm{pu} /$ - to measure lip movement, /tat/ - to measure tip of tongue movement, $/ \mathrm{ka} /$ - to measure movement of the back of the tongue, /tun/for the velum and /ha/ - to measure for breath control in articulation were repeated continuously as rapidly as possible for five minutes each.

Colour Stroop. Experimental data were collected on the colour Stroop task which comprised six conditions, including a base-line black word reading condition. These were presented on laminated cards. There was a short practice trial for each condition, followed by the experimental trial which is reported here. For each condition, there were four lines of six words per line.

Word search. Experimental data were collected on the Neisser type word-search tasks, comprising four conditions which are described in Gurd (1995b). Measures of rates of word-search through different categories of long-term semantic memory were obtained. The task involves silently scanning down vertical word lists, until a given target or category member is detected and read aloud.

\section{RESULTS}

The experimental results for Cases 1 and 2 are shown in Tables II and III. (Results for controls are shown in Table IV).

Automatic speech. Both patients were within normal limits on the automatic speech measures, which were of shorter duration than the articulation tasks.

Continuous series. Both subjects were impaired on this task. Case 1 was markedly impaired on continuous series with a rate score which fell $2.65 \mathrm{SD}$ below the control mean. She completed only one third of the tasks to criterion. Case 2's score was $1.70 \mathrm{SD}$ below the control mean but she completed only $17 \%$ of the tasks to criterion. 
Speeded picture naming. Speeded picture naming showed considerable slowing for both PSP patients. Given that Case 1's Z-scores (based on control values) fell considerably below those for articulation and automatic speech, these data probably indicate the presence of word-finding difficulties over and above any slowing due to articulatory problems. Case 1 named 0.47 pictures per second, a $Z$ score of -1.88 $\mathrm{SD}$ from the mean of the control group. Case 2 named only an average of 0.39 pictures per second, giving her a $\mathrm{Z}$ score of -2.90 ; in her case, it is more difficult to draw the distinction between articulatory and word-finding factors underlying her slowed picture naming.

Verbal fluency. On verbal fluency, Case 1 showed a selective task-switching impairment. She was within normal limits on single fluency (although poor on
WEAPONS and SPORTS), but she was considerably impaired on the alternating tasks $(Z=-2.25)$. Case 2, by contrast, was significantly impaired on all the verbal fluency categories. She also showed considerable decline on alternating (mean $\mathrm{Z}=-3.25$ ) over single $(Z=-2.76)$ fluency (see Table II).

Articulation: Both PSP subjects were slow at movement of the articulators: Boston Diagnostic Aphasia Battery (BDAE, Goodglass and Kaplan, 1972) lip and mouth measures were 10/12 for Case 1 and 5/12 for Case 2. For speeded word repetition from the BDAE, Case 1 was normal, but Case 2 was considerably slowed (score 8/14). On further single syllable repetitions, measuring lip, tip of tongue, back of tongue, velum movement and breath, Case 1 was slow but within normal limits while Case 2 was significantly slowed on all tasks.

TABLE II. PSP word-finding and articulation

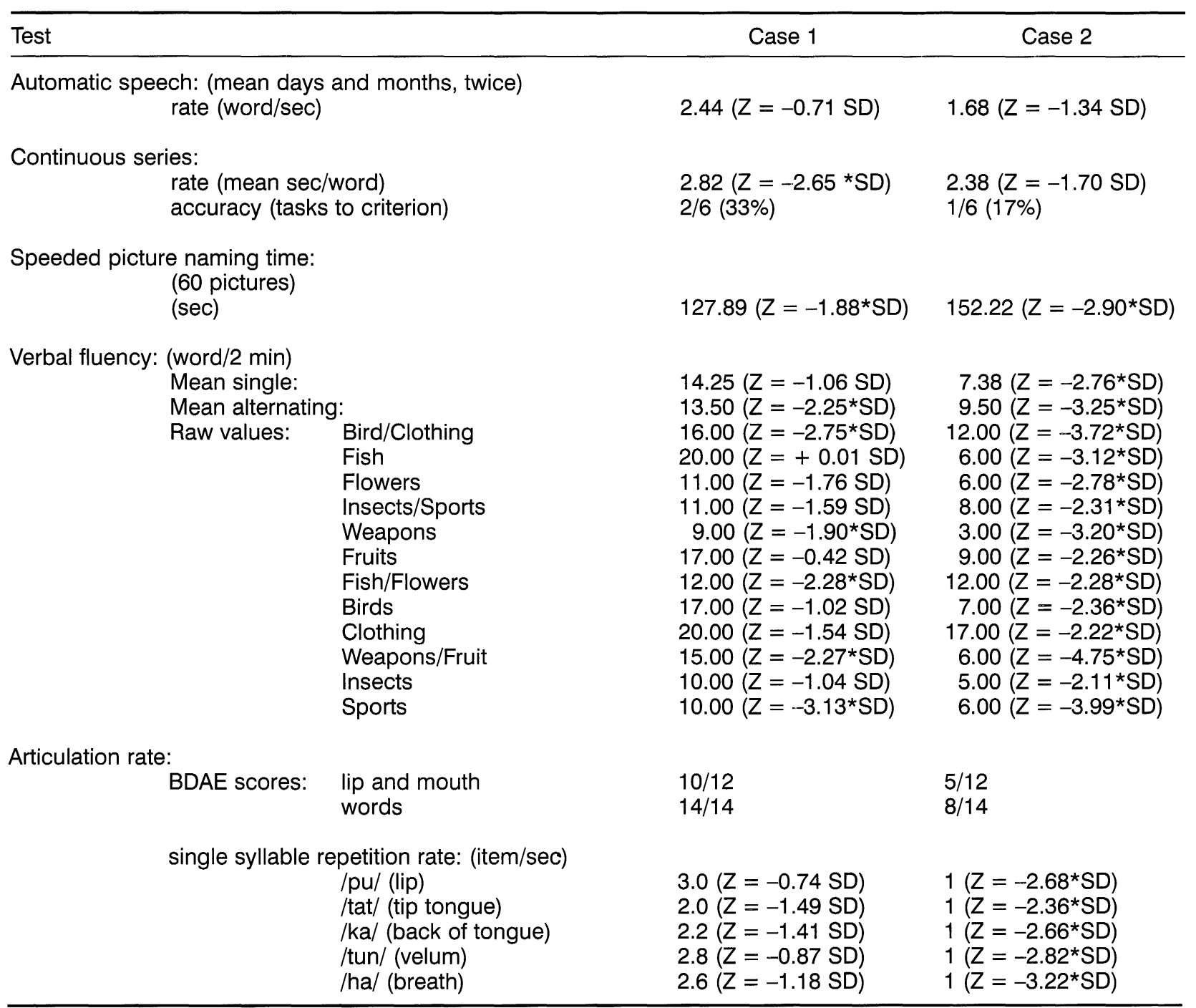

36 Behavioural Neurology . Vol 10 . 1997 
TABLE III. PSP Stroop experiment and word search

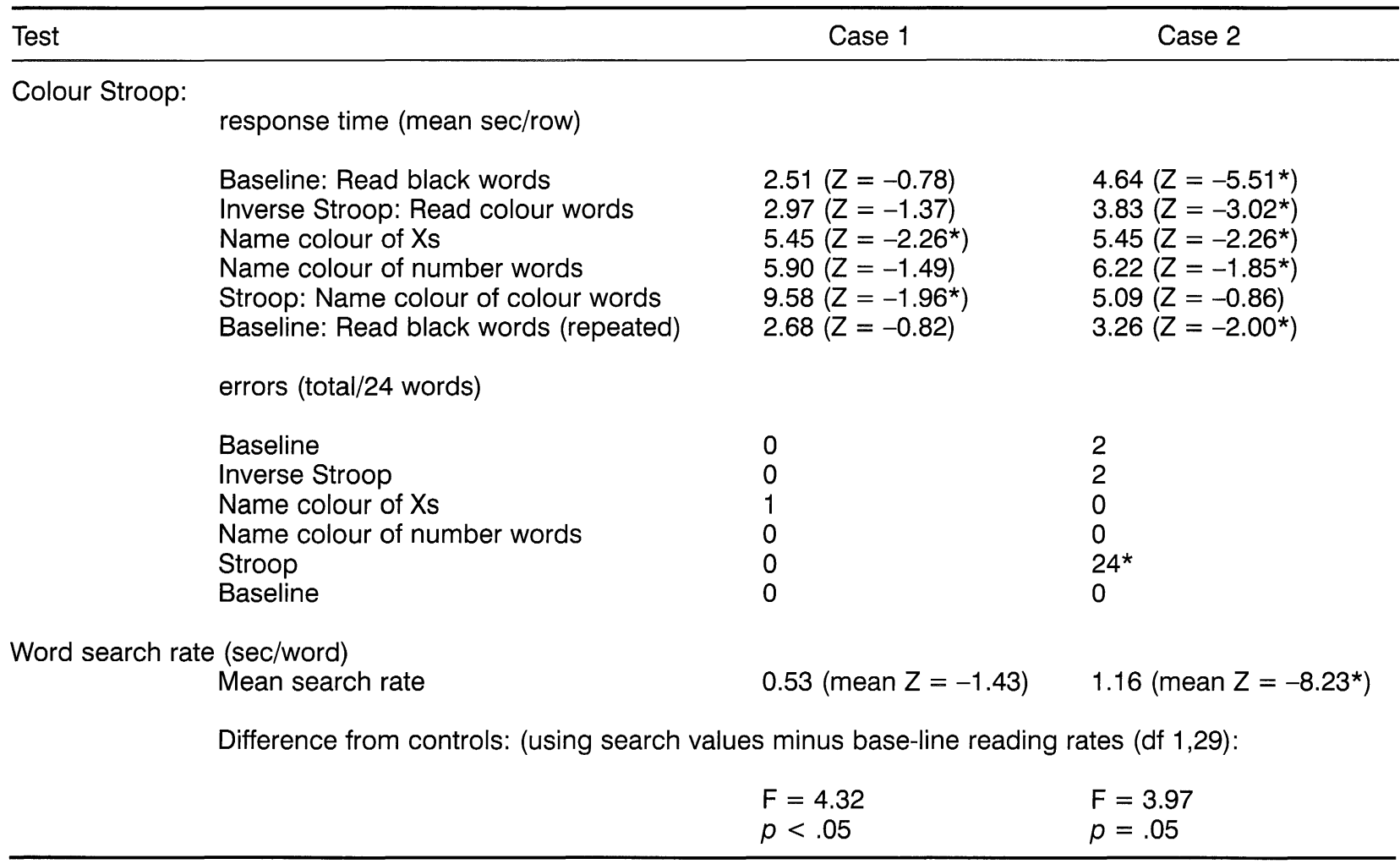

Key: * = significantly different from controls.

Colour Stroop. Both PSP patients were selectively impaired on the colour Stroop condition (see Table III). Case 1 was significantly slowed compared with controls; her Z-score based on control mean and SD was -1.96 . Case 2 was so impaired at colour Stroop that she made $24 / 24$ errors, and hence her time values do not adequately reflect her performance.

Word search. Both patients were significantly impaired, compared with controls, on the mean wordsearch tasks. Case 1 had a mean search time of 0.53 seconds per word ( df 1,29, $\mathrm{F}=4.32, p<.05)$. Her baseline oral reading rate was also significantly slowed compared with controls (0.74 seconds per word, Z-score based on control values $=-1.95)$. Case 2 had a mean search rate of 1.16 seconds per word ( $\mathrm{df}$ $1,29, \mathrm{~F}=3.97, p=.05)$, and a slowed oral reading baseline rate of 1.61 seconds per word (a Z-score of -9.60 , based on control values).

\section{DISCUSSION}

It has been claimed previously that semantic memory impairments are linked to impaired search and retrieval processes in patients with PSP (Litvan et al., 1989; Van der Hurk and Hodges, 1995). Evidence from two cases of PSP described here support such claims. The data confirm that naming and semantic memory impairments may occur in comparatively early onset PSP as part of multiple cognitive deficits. These are found in association with intact automatic speech, which requires minimum semantic search, but with impaired word-search performance (search through long-term lexical-semantic stores). There is an important distinction between the type of search impairment found in PSP and its significance to other semantic difficulties. Litvan (1994) demonstrated that Sternbergtype short term memory search is intact in PSP. Our data, by contrast, demonstrate impairment on Neissertype long term semantic memory search in patients with PSP.

Our data also support the distinction which has been drawn between the cognitive deficits of patients with PSP and those associated with dementia of the Alzheimer type (Van der Hurk and Hodges, 1995). Episodic memory, as evidenced by performance on the Wechsler paragraph recall and paired associates tasks was intact in our two cases, in agreement with Van der 
TABLE IV. Normal control results on experimental neuropsychology tests

\begin{tabular}{|c|c|c|c|}
\hline \multicolumn{2}{|l|}{ Test } & Mean (SD) & Range \\
\hline \multicolumn{2}{|c|}{ Automatic speech: (mean days and months, twice) } & 3.29 (SD 1.20) & $1.83-3.80$ \\
\hline Continuous series: & $\begin{array}{l}\text { rate (mean sec/word) } \\
\text { accuracy (tasks to criterion) }\end{array}$ & $\begin{array}{l}0.35(S D 0.93) \\
81 \%\end{array}$ & $\begin{array}{l}0.97-2.64 \\
50-100 \%\end{array}$ \\
\hline \multicolumn{2}{|c|}{ Speeded picture naming time: (60 pictures) (sec) } & 82.75 (SD 23.97) & $56.79-142.65$ \\
\hline $\begin{array}{r}\text { Verbal fluency: (word/2 m } \\
\text { Mean single: } \\
\text { Mean alterna } \\
\text { Raw values: }\end{array}$ & $\begin{array}{l}\text { in) } \\
\text { ting: } \\
\text { Bird/Clothing } \\
\text { Fish } \\
\text { Flowers } \\
\text { Insects/Sports } \\
\text { Weapons } \\
\text { Fruits } \\
\text { Fish/Flowers } \\
\text { Birds } \\
\text { Clothing } \\
\text { Weapons/Fruit } \\
\text { Insects } \\
\text { Sports }\end{array}$ & $\begin{array}{l}20.89 \text { (SD 6.24) } \\
22.51 \text { (SD 5.30) } \\
27.30 \text { (SD 4.11) } \\
19.95 \text { (SD 4.47) } \\
19.65 \text { (SD 4.91) } \\
17.60 \text { (SD 4.16) } \\
17.80 \text { (SD 4.63) } \\
18.85 \text { (SD 4.36) } \\
21.90 \text { (SD 4.35) } \\
24.60 \text { (SD 7.47) } \\
26.80 \text { (SD 4.41) } \\
23.25 \text { (SD 3.63) } \\
14.90 \text { (SD 4.69) } \\
24.60 \text { (SD 4.66) }\end{array}$ & $\begin{array}{l}17.13-31.13 \\
18.25-31.00 \\
22-36 \\
14-31 \\
10-31 \\
11-28 \\
13-30 \\
11-31 \\
11-29 \\
14-25 \\
21-36 \\
19-30 \\
8-25 \\
18-38\end{array}$ \\
\hline $\begin{array}{l}\text { Articulation rate: } \\
\qquad \begin{array}{r}\text { BDAE scores } \\
\text { Single syllabl }\end{array}\end{array}$ & $\begin{array}{l}\text { lip and mouth } \\
\text { words } \\
\text { e repetition rate: (item/sec) } \\
\text { /pu/ (lip) } \\
\text { /tat/ (tip tongue) } \\
\text { /ka/ (back of tongue) } \\
\text { /tun/ (velum) } \\
\text { /ha/ (breath) }\end{array}$ & $\begin{array}{l}9.60 \text { (SD 1.78) } \\
14.00 \text { (SD 0.00) } \\
3.76(\text { SD 1.03) } \\
3.71 \text { (SD 1.15) } \\
3.55 \text { (SD 0.96) } \\
3.76 \text { (SD 0.98) } \\
3.64(\text { SD } 0.82)\end{array}$ & $\begin{array}{l}8-12 \\
14-14 \\
2.4-5.40 \\
2.2-5.80 \\
2.0-5.00 \\
2.0-5.00 \\
3.0-5.00\end{array}$ \\
\hline \multicolumn{4}{|c|}{$\begin{array}{l}\text { Colour Stroop: } \\
\qquad \text { Response time (mean sec/row) }\end{array}$} \\
\hline & $\begin{array}{l}\text { Baseline: Read black words } \\
\text { Inverse Stroop: Read colour words } \\
\text { Name colour of Xs } \\
\text { Name colour of number words } \\
\text { Stroop: Name colour of colour words } \\
\text { Baseline: Read black words (repeated) } \\
\text { Errors (mean/row) }\end{array}$ & $\begin{array}{l}2.16 \text { (SD 0.45) } \\
2.26 \text { (SD 0.52) } \\
3.71 \text { (SD } 0.77) \\
4.57 \text { (SD } 0.89) \\
6.46 \text { (SD 1.59) } \\
2.28 \text { (SD 0.49) }\end{array}$ & $\begin{array}{l}1.53-3.39 \\
1.60-3.81 \\
2.58-5.46 \\
3.07-6.95 \\
4.85-10.69 \\
1.66-3.75\end{array}$ \\
\hline & $\begin{array}{l}\text { Baseline } \\
\text { Inverse Stroop } \\
\text { Name colour of Xs } \\
\text { Name colour of number words } \\
\text { Stroop } \\
\text { Baseline }\end{array}$ & $\begin{array}{l}0.03 \text { (SD } 0.11) \\
0.00 \text { (SD } 0.00) \\
0.04 \text { (SD } 0.09) \\
0.03 \text { (SD } 0.08) \\
0.13(\text { SD } 0.25) \\
0.00 \text { (SD } 0.00)\end{array}$ & $\begin{array}{l}0-0.50 \\
0-0 \\
0-0.25 \\
0-0.25 \\
0-0.75 \\
0-0\end{array}$ \\
\hline Word search mean rate & & 0.39 (SD 0.07) & $0.30-0.45$ \\
\hline
\end{tabular}

Hurk and Hodges (1995). These findings are consistent with the prediction that word-search difficulties underlie the poor verbal fluency performance. On tests of working memory, Case 1 showed intact performance (digit spans and block tapping span). It appears, however, that digit span impairments may arise with progressive severity of the disease, since Case 2 scored significantly below the controls. Task alternation proved to be particularly difficult for the PSP subjects. The performance of Case 1, whose disease was less severe, showed a severely impaired performance of task alternation; on the Wisconsin Card Sorting Test

38 Behavioural Neurology • Vol 10 . 1997 
she did not attain any categories. Case 2 was too impaired to attempt it. On continuous series, both patients performed very poorly. Case 1 completed only a third of the tasks to criterion and her mean time was 2.65 SD below the control mean, while Case 2 completed $17 \%$ of the tasks to criterion and attained a rate score which fell 1.7 SD below the control mean. The verbal fluency profiles showed further evidence of task-alternation difficulties for Case 1, who was significantly impaired on three of four of the alternating categories, despite being intact on some of their single equivalents. Case 2, by contrast, was not capable of normal performance on any of the eight single, or four alternating two-minute fluency tasks; she was profoundly impaired, scoring a single fluency mean of 7.38 words in 2 minutes (2.14 SD below the control mean) and an alternating mean of 9.5 words in 2 minutes (2.45 SD below the control mean).

Both subjects showed substantial impairments on the Stroop experiment. Case 1 was significantly slowed on Stroop as well as in the colour naming of Xs (a control condition), and Case 2 was totally incapable of performing the Stroop condition. This finding is in keeping with previous work which has shown deficits in the orienting of visual attention in PSP. For instance, Rafal et al. (1988) demonstrated that PSP patients were slower than controls at directing their visual attention and were slower than PD patients in the vertical plane. Kimura et al. (1981) also reported impairments on cognitive tests requiring visual scanning, although no effort was made to deduct the purely visual effects from the cognitive effects in this study.

Neurolinguistic investigations have shown deficits in spontaneous speech, articulation, prosody, comprehension, repetition of single phonemes and onesyllable words, written language, reading aloud, writing to dictation, naming to confrontation of objects, colours, and situations, as well as auditory and reading comprehension (words and sentences). In a study conducted by Podoll et al.(1991) the six cases were not described in individual detail but the authors commented that picture-naming results may have arisen from visual problems with the stimulus inspection. In a single case described by Lebrun et al. (1986), verbal fluency was impaired but picture naming was not. There was no agraphia but paligraphia or perseverative copying of the stimulus was reported. Articulation was hypokinetic and slurred, voice was muffled, and pitch range was reduced. The patient stuttered with repetitions of syllables and short words but there was no evidence of aphasia in his use of everyday language. He performed well on a variety of metalinguistic tasks and showed no signs of agnosia or apraxia. He was dyscalculic and had difficulty with visual and visuoconstructive tasks. He did not appear demented at the time of testing but he did suffer from emotional lability.

It is frequently stated that executive dysfunction appears early in the course of the disease and that it is relatively severe (Litvan, 1994). Evidence from our study would corroborate this claim. There are clear indications of task-switching problems, as measured on continuous series, in our study. In terms of background neuropsychology, Case 1 also showed normal shortterm and anterograde episodic memory but impaired Stroop performance. Her automatic speech rate was within normal limits, despite the articulatory slowing typical of PSP (Kluin et al., 1990). She was significantly impaired on five out of 12, two-minute verbal fluency tasks and, of these, she was impaired on three of four of the alternating fluency tasks. She was the less severely affected of the two patients being ambulatory and independent, with only mild visual scanning deficits on neurological examination. Her cognitive impairments were observed using cerebral perfusion measurements; they were only just outside normal limits.

Case 2, by contrast, was much more impaired neurologically and she had a lower estimated pre-morbid IQ. She required assistance in walking and showed clearly reduced frontal cerebral perfusion on HMPAOSPECT scan. The initial clinical impression that she might be globally demented proved not to be the case. Despite impaired auditory verbal short-term memory, she performed well on the Wechsler paragraph recall test and on the Stroop test, despite her frontal hypoperfusion, visual problems, and articulatory difficulties (Behrman et al., 1969; Kluin et al., 1993). She also performed well on Warrington's naming to description task which has no visual component but requires naming to orally presented verbal definitions. Her performance was just within normal limits on continuous series but, given that she only attained $17 \%$ of the tasks to criterion, she was actually impaired on this task. She tended to break down and not complete a given set or to decline to perform the difficult sets. Clear impairments were noted on the two-minute verbal fluency experiment. She was significantly impaired on all 12 tasks; these results corroborate those of Maher et al. (1985).

The word-finding impairments of PSP patients are similar to those of PD patients but they are more severe and less amenable to cued-remediation. Whereas PD patients may be intact on speeded picture naming because of cued facilitation (Gurd and Marshall, 1995) the PSP cases described here were not. These qualitative and quantitative differences may be 
related to the fact that neurotransmitter systems, other than the dopaminergic ones, are typically affected in PSP patients. These neurotransmitter systems include the cholinergic systems (Kish et al., 1985; Foster et al., 1988; Heilman and Valenstein, 1993; Gearing et al., 1994; Riley et al., 1994).

It can be concluded that PSP patients tend to develop semantic memory impairments as the disease progresses, as evidenced in tasks of picture naming. Articulation also becomes impaired. In the earlier stages of the disease, word-finding performance may be optimized by using non-visual methods of testing, such as naming to oral definition (Esmonde et al., 1996). Working memory impairments also arise and affect functions such as task-switching. These cases show that it is possible for a PSP patient with demonstrated frontal lobe hypoperfusion (on SPECT scan) to have selective neuropsychological impairment on some tasks, such as picture naming, while retaining normal values in other tasks, such as Stroop. These latter tasks are associated typically with frontal lobe dysfunction. Such data are supportive of the theoretical fractionation of frontal lobe functions (Gurd, 1995a).

\section{Acknowledgements}

This work was supported by the Medical Research Council. We are grateful to the patients and their families for their participation, and to Mrs. P. Dobson, for assistance with the manuscript.

\section{REFERENCES}

Agid Y, Javoy-Agid F, Ruberg M, Pillon B, Dubois B, Duychaerts C, Hauw J-J, Baron J-C and Scatton B (1986) Progressive supranuclear palsy: Anatomoclinical and biochemical considerations. In: Advances in Neurology Vol. 45. (Eds MD Yahr and KL Bergmann), pp. 191-206. Raven Press, New York.

Agid Y, Javoy-Agid F, Ruberg M and Hirsch E (1989) Dopaminergic systems in Parkinson's Disease. In: Disorders of Movement, Clinical, Pharmacological and Physiological Aspects (Eds NP Quinn and PG Jenner), pp. 85-113. Academic Press, London.

D'Antona R, Baron JC, Samson Y, Serdaru M, Viader F, Agid Y and Cambier J (1985) Subcortical dementia. Frontal cortex hypometabolism detected by positron emission tomography in patients with progressive supranuclear palsy. Brain 108, 785-799.

Barr AN (1986) Progressive supranuclear palsy. Handbook of Clinical Neurology Vol. 5 (49): Extrapyramidal Disorders. (Eds PJ Vinken, GW Bruyn and HK Klawans), pp. 239-254. Elsevier Science Publishers, Amsterdam.

Behrman S, Carroll JD, Janota E and Matthews WB (1969) Progressive supranuclear palsy. Clinicopathological study of four cases. Brain 92, 663-678.

Benton AL (1974) Visual Retention Test. Psychological Corporation, New York, NY.

Berg EA (1948) A simple objective technique for measuring flexibility in thinking. Journal of Genetic Psychology 39, 15-22.
Burgess PW and Shallice T (1994) Fractionnement du syndrome frontal. Revue de Neuropsychologie 4, 345-370.

Coughlan AK and Warrington EK (1978) Word comprehension and word retrieval in patients with localised cerebral lesions. Brain 101, 163-185.

Daniel SE, de Bruin VMS and Lees AJ (1995) The clinical and pathological spectrum of Steele-RichardsonOlszewski syndrome (progressive supranuclear palsy): a reappraisal. Brain 118, 759-770.

Esmonde T, Giles E, Zuereb J and Hodges J (1996) Progressive supranuclear palsy presenting with dynamic aphasia. Journal of Neurology, Neurosurgery, and Psychiatry, 60, 403-410.

Foster NL, Gilman S, Berent S, Morin EM, Brown MB and Koeppe RA (1988) Cerebral hypometabolism in progressive supranuclear palsy studied with positron emission tomography. Annals of Neurology 24, 399-406.

Frith CD, Friston KJ, Liddle PF and Frackowiak RSJ (1991) A PET study of word-finding. Neuropsychologia 29, 1137-1148.

Gearing M, Olson DA, Watts RL and Mirra SS (1994) Progressive supranuclear palsy: Neuropathologic and clinical heterogeneity. Neurology 44, 1015-1024.

Goodglass H and Kaplan E (1972) The Assessment of Aphasia and Related Disorders. Lea and Febiger, Philadelphia, PA.

Goodglass H and Kaplan E (1983) The Boston Naming Test. Lea and Febiger, Philadelphia, PA.

Gurd JM (1993) Studies of Verbal Fluency Deficits in Patients with Parkinson's Disease. D. Phil. Thesis, Oxford University.

Gurd JM (1995a) Frontal dissociations: Evidence from Parkinson's Disease. Journal of Neurolinguistics 9, 55-68.

Gurd JM (1995b) Word search in patients with Parkinson's Disease. Journal of Neurolinguistics 9, 207-218.

Gurd JM and Marshall JC (1995) Mechanisms of wordretrieval: Neuropsychological investigations of patients with Parkinson's Disease. In: Speech and Reading: $A$ Comparative Approach. (Eds B de Gelder and H Morais) pp. 339-351, Erlbaum (UK), East Sussex.

Heilman KM and Valenstein E (Eds) (1993) Clinical Neuropsychology, Third Edition. Oxford .University Press, Oxford.

Kimura D, Barnett HJM and Burkhart G (1981) The psychological test pattern in progressive supranuclear palsy. Neuropsychologia 19, 301-306.

Kish SJ, Chang LJ, Mirchandani L, Shannak K and Hornykiewica O (1985) Progressive supranuclear palsy: Relationship between extrapyramidal disturbances, dementia, and brain neurotransmitter markers. Annals of Neurology 18, 530-536.

Kluin KJ, Foster NL, Gilman S and Berent S (1990) Speech disorders in progressive supranuclear palsy. Neurology 40, 424.

Kluin KJ, Norman LF, Berent S and Gilman S (1993) Perceptual analysis of speech disorders in progressive supranuclear palsy. Neurology 43, 563-566.

Lebrun Y, Devreux F and Rousseau J-J (1986) Language and speech in a patient with a clinical diagnosis of progressive supranuclear palsy. Brain and Language 27, 247-256.

Lees AJ (1987) The Steele-Richardson-Olszewski syndrome (progressive supranuclear palsy). In: Movement Disorders 2 (Eds D Marsden and S Fahn), pp. 272-287. 
Butterworth, London.

Litvan I, Agid Y, Calne D, Campbell G, Dubois B, Duvoisin RC, Goetz CG, Golbe LI, Grafman J, Growdon JH, Hallet M, Jankovic J, Quinn NP, Tolosa E and Zee DS (1996) Clinical research criteria for the diagnosis of progressive supranuclear palsy (SteeleRichardson-Olszewski syndrome): Report of the NINDS-SPSP International Workshop. Neurology 47, $1-9$.

Litvan I (1994) Cognitive disturbances in progressive supranuclear palsy. Journal of Neural Transmission 42, 69-78.

Litvan I, Grafman J, Gomez C and Chase TN (1989) Memory impairment in patients with progressive supranuclear palsy. Archives of Neurology 46, 765-767.

Maher ER, Smith EM and Lees AJ (1985) Cognitive deficits in the Steele-Richardson-Olszewski syndrome (progressive supranuclear palsy). Journal of Neurology, Neurosurgery and Psychiatry 48, 1234-1239.

Nelson HE and O'Connell A (1978) Dementia: The estimation of premorbid intelligence levels using the new adult reading test. Cortex 14, 234-244.

Pierrot-Deseilligny C, Rivaud S, Pillon B, Fournier E and Agid Y (1989) Lateral visually-guided saccades in progressive supranuclear palsy. Brain 112, 471-487.

Pillon B, Gouider-Khouja N, Deweer B, Vidailhet M, Malapani C, Dubois B and Agid Y (1995) Neuropsychological pattern of striatonigral degeneration: comparison with Parkinson's disease and progressive supranuclear palsy. Journal of Neurology, Neurosurgery, and Psychiatry 58, 174-179.

Podoll K, Schwarz M and Noth J (1991) Language functions in progressive supranuclear palsy. Brain 114, 1457-1472.

Rafal RD, Posner MO, Friedman JH, Inhoff AW and Bernstein E (1988) Orienting of visual attention in progressive supranuclear palsy. Brain 111, 267-280.

Raven JC (1958) Standard Progressive Matrices H.K. Lewis and Co. Ltd., London.
Rey A (1941) Lexamen psychologique dans les case d'encephalopathie traumatique. Archives de Psychologie 28, 286-340.

Riley DE, Fogt N and Leigh RJ (1994) The syndrome of 'pure akinesia' and its relationship to progressive supranuclear palsy. Neurology 44, 1025-1029.

Rosser AE and Hodges JR (1994) Initial letter and semantic category fluency in Alzheimer's Disease, Huntington's disease, and progressive supranuclear palsy. Journal of Neurology, Neurosurgery, and Psychiatry 57, 1389-1394.

Sawashima M (1980) Some notes on the physiology of speech production. Language and Speech 23, 31-37.

Snodgrass JG and Vanderwart M (1980) A standardized set of 260 pictures: Norms for name agreement, image agreement, familiarity and visual complexity. Journal of Experimental Psychology: Human Learning and Memory 6, 174-215.

Steele JC, Richardson JC and Olszewski J (1964) Progressive supranuclear palsy. Archives of Neurology 10, 333-359.

Van der Hurk PR and Hodges JR (1995) Episodic and semantic memory in Alzheimer's Disease and Progressive Supranuclear Palsy: A comparative study. Journal of Clinical and Experimental Neuropsychology 17, 459-471.

Wechsler D (1945) A standardized memory scale for clinical use. Journals of Psychology 19, 87-95.

Wechsler D (1981) Wechsler Adult Intelligence Scale-Revised. The Psychological Corporation, Harcourt Brace Jovanovich Publishers, Cleveland, Ohio.

Young AB (1985) Progressive supranuclear palsy: postmortem chemical analysis. Annals of Neurology 18, 521-522.

Zigmond AS and Snaith RP (1983) Hospital anxiety and depression (HAD) scale. Acta Psychiatrica Scandinavica 67, 361-370.

(Received 11 January 1996; accepted 18 January 1997). 


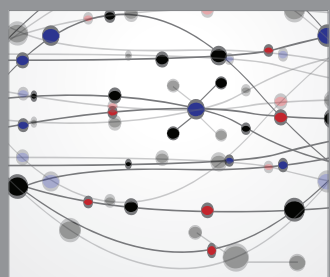

The Scientific World Journal
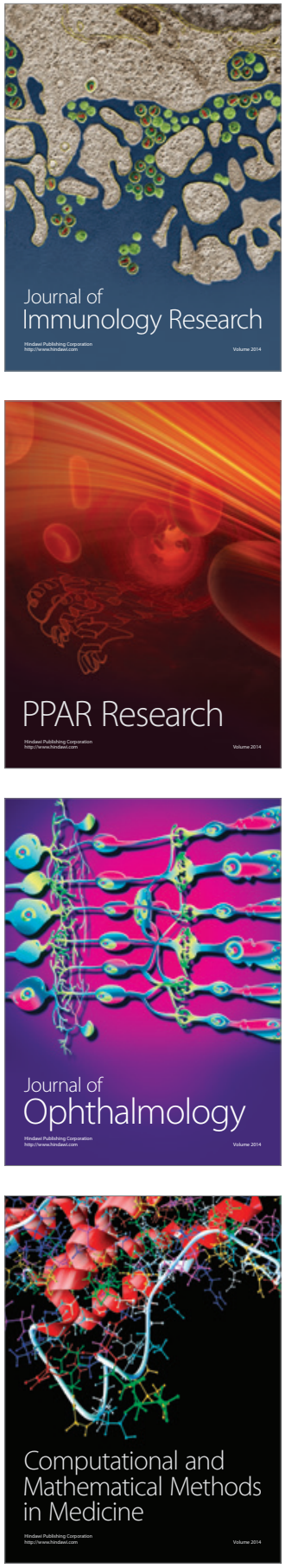

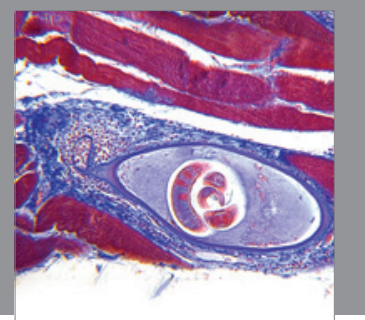

Gastroenterology

Research and Practice
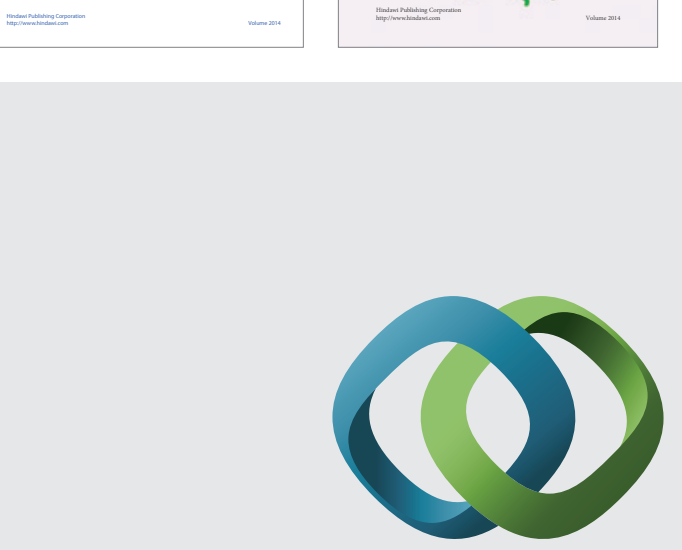

\section{Hindawi}

Submit your manuscripts at

http://www.hindawi.com
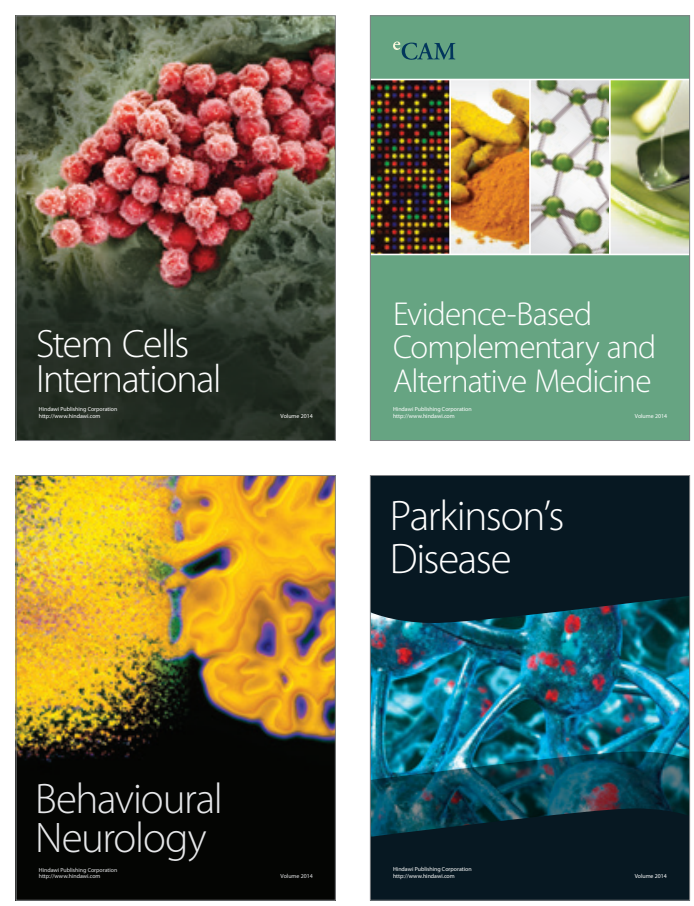

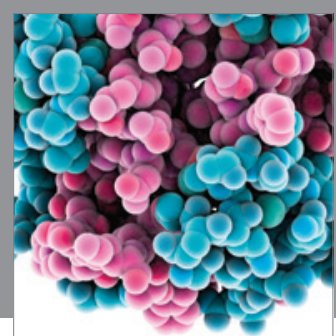

Journal of
Diabetes Research

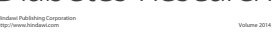

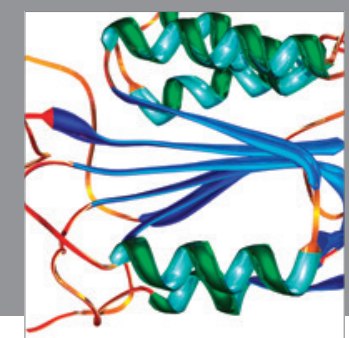

Disease Markers
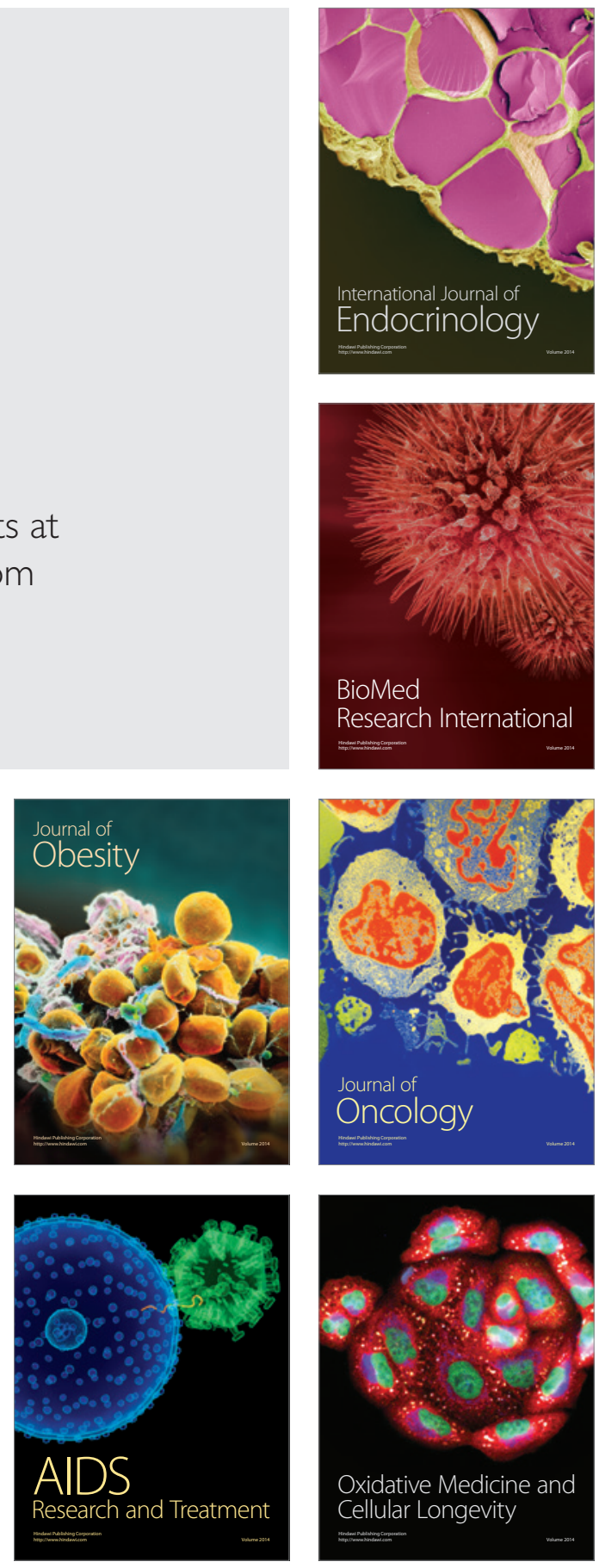